\title{
Impacts of climate change on marine ecosystem production in fisheries-dependent societies
}

M. Barange, G. Merino, J.L. Blanchard, J. Scholtens, J. Harle, E.H. Allison, J.I. Allen, J. Holt, S. Jennings

\section{Author information}

\section{Affiliations}

Plymouth Marine Laboratory, Prospect Place, Plymouth PL1 3DH, UK Manuel Barange, Gorka Merino \& J.Icarus Allen

National Oceanography Centre, Joseph Proudman building, 6 Brownlow Street, Liverpool L3 5DA, UK

Jason Holt \& James Harle

School of Marine and Environmental Affairs, University of Washington, 3707 Brooklyn Ave NE, Seattle 98105 WA USA

Edward $\mathrm{H}$. Allison

Centre for Environment, Fisheries and Aquaculture Science, Lowestoft Laboratory, Pakefield Rd, Lowestoft NR33 OHT, UK and School of Environmental Sciences, University of East Anglia, Norwich NR4 7TJ, UK

Simon Jennings

Department of Animal and Plant Sciences, University of Sheffield, Western Bank, Sheffield S10 2TN, UK

Julia L. Blanchard

MARE Centre for Maritime Research, Amsterdam Institute for Social Science Research, University of Amsterdam, Plantage Muidergracht 14, 1018 Amsterdam, The Netherlands Joeri Scholtens

AZTI-Tecnalia, Marine Research Division, Herrera Kaia, Portualdea s/n, 20110 Pasaia, Spain

Gorka Merino

\section{Contributions}

M.B. designed the study and wrote the text. J.I.A., J.Harle and J.Holt designed and conducted the physical-biological model runs. J.L.B and S.J. designed the size-based approach and model. J.L.B. conducted model runs and summarized outputs. G.M. contributed to the sizebased fisheries outputs and prepared the figures. E.H.A. and J.S. computed the dependency estimates. All authors contributed to the text.

\section{Competing financial interests}

The authors declare no competing financial interests.

\section{Corresponding author}

Correspondence to Manuel Barange, m.barange@pml.ac.uk, +44-(0)1752 633160

\section{Growing human populations and changing dietary preferences are increasing global}

1 Barange et al. Impacts of climate change on marine ecosystem production in fisheries dependent societies 
2 demands for fish $^{1}$, adding pressure to concerns over fisheries sustainability ${ }^{2}$. Here we

3 develop and link models of physical, biological and human responses to climate change

4 in 67 marine national Exclusive Economic Zones (EEZ), which yield ca $60 \%$ of global fish

5 catches, to project climate change yield impacts in countries with different dependency

6 on marine fisheries ${ }^{3}$. Predicted changes in fish production indicate increased

7 productivity at high latitudes and decreased productivity at low/mid latitudes, with considerable regional variation. Overall, increases and decreases by 2050 are estimated to change by $<10 \%$ (mean $+3.4 \%$ ) from present yields. Among the nations showing a high dependency on fisheries ${ }^{3}$, climate change is predicted to increase productive potential in West Africa and decrease it in South and Southeast Asia. Despite projected population increases and per capita fish consumption rates ${ }^{1}$, ongoing technological development in the aquaculture industry suggest that projected global fish demands in 2050 could be met, challenging existing predictions of inevitable shortfalls in fish supply by the mid-21 ${ }^{\text {st }}$ century ${ }^{4}$. This conclusion, however, is contingent on successful implementation of strategies for sustainable harvesting and effective distribution of wild fish products from nations and regions with a surplus to those with a deficit. Changes in management effectiveness ${ }^{2}$ and trade practices ${ }^{5}$ will remain the major influence on realized gains or losses in global fish production.

Marine fisheries provide 80Mt of protein and micronutrient-rich food for human consumption per year and contribute US $\$ 230$ billion to the global economy, offering livelihood support to $8 \%$ of the world's population ${ }^{5}$. With demand for fish products predicted to increase, efforts to support

24 food and livelihood security need to be informed by predictions of changes in fish production and their societal and economic consequences. Biological predictions based on OceanAtmosphere General Circulation Models (GCMs), have demonstrated that climate change will modify the physical and chemical properties of the oceans, affecting the productivity, distribution, seasonality and efficiency of food webs, from primary producers ${ }^{6}$ to fish ${ }^{7,8}$. However, using GCMs to predict fish production has several uncertainties, in addition to their

30 structural and natural variability uncertainties ${ }^{9}$. First, the resolution of (GCMs) is too coarse 31 (typically $1-2^{\circ}$ ) to capture the processes that dominate the dynamics of the world's coastal and 
shelf regions, such as coastal upwelling and tidal mixing ${ }^{10}$, and display significantly different responses to climate than the open ocean. Directly addressing the effects of these processes is

34 an important challenge because coastal and shelf regions contribute a quarter of the global primary production and the large majority of the global fish production ${ }^{11}$. Second, predicting the impacts of climate change on ecosystem and fish production remains a major challenge, as it depends on the transfer of energy through complex and often compensatory food chain processes $^{12}$. Current approaches have either strong habitat or energy transfer assumptions ${ }^{8,13}$, or focus on predicting impacts on individual species ${ }^{14}$.

Here we directly address these challenges by developing and applying a highly resolved coupled physical-biological shelf-seas model to 67 marine national EEZs. The model was forced using a single GCM (IPSL-CM4) under the IPCC SRES A1B scenario, providing 10-year mean outputs for present day and ca 2050. These were used to drive a dynamic size-based food web model to estimate the ecological consequences of climate change on fish production capacity. Finally, we evaluate the societal relevance of these results by looking at the dependency of individual countries on their fisheries sectors in terms of food and livelihood security, and at the expected global demand for fish products for a growing human population.

50 Our results show that in all the shelf regions considered the mixed layer depth temperature 51 (MLDT, the depth to which the density difference from the surface $<0.03 \mathrm{~kg} \cdot \mathrm{m}^{-3}$ ) is expected to 52 increase referenced to present day. By 2050 predicted warming of the mixed layer of shelf seas will range from a moderate $0.2^{\circ} \mathrm{C}$ in the Irish EEZ to $2.9^{\circ} \mathrm{C}$ off Korea and East China (Figure 1a, $542 \mathrm{a})$.

56 Our models predict average increases in net primary production (NPP) of shelf seas of about $5714 \%$, slightly larger but consistent with existing estimates of global primary production change 58 based on coarse-scale GCMs ${ }^{6}$. Ecosystems in higher (lower) latitudes will generally experience 59 production increases (decreases) (Figure 1b, 2a). An important consideration to understand 60 these results is that shelf regions are only seasonally stratified, a distinction generally omitted 61 from global $\mathrm{GCMs}^{10}$, which often predict decreased primary production in the open ocean as a 
result of increased permanent stratification. The balance of NPP across phytoplankton size classes is also predicted to change by 2050 , with flagellates (size class $2-20 \mu \mathrm{m}$ ) expected to increase by a global average of $10.2 \%$ versus $3.3 \%$ for diatoms (size class $>20 \mu \mathrm{m}$ ), reflecting a shift to more recycled production. This differential trend is consistent with contemporary observations ${ }^{15}$ and modelled predictions ${ }^{16}$. Smaller phytoplankton is expected to support longer food chains with lower overall transfer efficiency ${ }^{16}$.

Global fisheries production potential was estimated to increase by a moderate $3.4 \%$ on average, with differential regional responses ${ }^{17}$ (Figure 2a). In general, results indicate that fisheries production is governed by available primary production ${ }^{18}$. The largest average increases in fish catch potential are predicted in the Nordic Sea (29.3\%), Gulf of Guinea (23.9\%) and the Kuroshio Current region (21.3\%). The largest average decreases are expected in the Canary Current (-14.6\%) and in the North Western American shelf region (-13.2\%). At EEZ level, Peruvian potential catch is predicted to decrease significantly while increasing in Iceland and Norway.

To indirectly validate our fish production algorithms we forced our models with Ocean and Atmospheric reanalysis data sets used to provide boundary conditions to the physicalecosystem model. Fish production estimates were compared with EEZ catch data, assuming a community fishing mortality rate of $0.8 \mathrm{yr}^{-117}$. Model predictions fall within the range of observations, despite some differences in some upwelling regions and/or small geographical areas ${ }^{17}$. Additional validation of our results can be found in related studies that examine fish production dynamics and potential fish yields in greater detail ${ }^{4,17}$.

86 Bio-climate envelope approaches have recently predicted a 30-70\% increase in fish catch 87 potential in high latitudes, and a $40 \%$ drop in the tropics, with a global $1 \%$ overall increase by $882050^{7,8}$. Our predictions are consistent with this despite being based on models that simulate 89 differently the ecological processes leading to fish production, reflecting that primary production 90 and temperature changes underpin both approaches. However, downscaling to regional or 91 national scales highlights uncertainties and contradictions between models. We predict 
significant decreases in production in the California Current region ${ }^{17}$, consistent with species based projections ${ }^{8}$, but contrary to a size-based projection based on a low resolution model

94 framework ${ }^{19}$. We predict increases in potential fish production in the Gulf of Guinea, while a

95 different OA-GCM model combination and a species-based bioclimate model predicted 8-26\%

96 decline in fish landings by $2050^{20}$. It is not surprising that different modelling frameworks result

97 in different quantitative projections. Our higher resolution shelf models are likely to be better at

98 capturing the dynamics of, for example, coastal upwelling systems, but in general the use of

99 single models to project complex physical-chemical processes has limitations which would be

100 better addressed through ensemble modelling approaches ${ }^{21}$.

101

102 How significant are the expected biological impacts to the economies of the countries exploiting

103 them? Among the nations covered, those most nutritionally and economically dependent on

104 fisheries are in West Africa (from Senegal to Nigeria), the Bay of Bengal (Bangladesh and

105 Burma) and in SE Asia (Indonesia, Cambodia), with fisheries also playing a significant role in

106 the economies and food systems of Peru and Ecuador, Iceland, NW and SW Africa, India,

107 Thailand, Vietnam and Japan (Figure 3). While other nations such as Norway, Chile and China

108 have globally significant marine fisheries interests, these countries also have large diverse

109 economies to which fisheries contribute little in overall terms. Combining dependency with

110 projected impact of climate change on fish catches (Figure 4) suggests that these impacts will

111 be of greatest concern to the nations of South and South East Asia, South West Africa (from

112 Nigeria south to Namibia), Peru, and some tropical small-island developing states ${ }^{22}$. These

113 countries rely relatively heavily on their fisheries sector in terms of wealth, food and employment

114 creation, while climate change is projected to negatively impact their potential fish catches.

115 Marine fishery dependent nations that may benefit from climate change effects on fisheries are

116 mostly along the West African coast (from Benin north to Mauritania), and Iceland.

118 Our results indicate greater instances of predicted negative impacts in parts of the tropics. Least

119 Developed Countries (LDC) in tropical regions have already been identified as particularly

120 vulnerable to climate change ${ }^{23}$, because of their greater economic and nutritional dependence

121 on fish and fewer available resources to invest in climate adaptation ${ }^{3}$. Thus, there is an

5 Barange et al. Impacts of climate change on marine ecosystem production in fisheries dependent societies 
122 expectation that climate change would have more significant consequences (positive or

123 negative) for marine-based food, income and revenue provision, for fishery-dependent

124 developing nations. Human population growth is likely to be faster in LDCs, where fish provide a

125 larger contribution to non-grain protein needs. South Asia stands out (Figure 4) as the region

126 which is not only projected to face decreasing catches, but also has a high fisheries

127 dependency and a sizable, rapidly growing population whose consumption of fish is likely to

128 increase with its rapid economic development ${ }^{1,23}$. The importance of quantifying regional

129 impacts of climate change to develop adaptation programmes and achieve global food security

130 targets in the future cannot be emphasized enough $\mathrm{h}^{4,24}$.

132 While climate change will alter the current geographical distribution of shelf sea ecosystems

133 productivity, in most of the regions and EEZs considered the overall potential impact on fish

134 production is projected to be low to moderate $( \pm 10 \%)$, highlighting the importance of other

135 factors such as management strategies over direct climate effects ${ }^{2}$. This partially reflects the

136 relatively short projection period considered in climate change terms. Longer projections would

137 have more significant but also more uncertain impacts, including changes to coral reefs and

138 other habitat-forming species, and to ocean acidification. Combined, climate change and

139 exploitation impacts are likely to be of greatest concern in maritime countries of South and

140 Southeast Asia, where fishing pressure is already very high and poorly regulated. However,

141 these countries have some of the world's fastest-growing aquaculture industries. With

142 decreasing dependence of aquaculture on wild-caught fishmeal, aquaculture expansion could

143 make a significant contribution to food security as the region adapts to climate change. West

144 African nations may see increased production in their EEZs by 2050 and, if their coastal people

145 are to benefit, a key task would be to ensure that fisheries governance improves and that

146 distant-water fishing nations do not jeopardize local opportunities to benefit from increased

147 productivity and value of their fisheries.

148

149 Our predictions of EEZ-based fish production changes have been used, in combination with

150 country-level scenarios of human population growth, trade models of fishmeal and fish oil, and

151 aquaculture development scenarios, to explore the conditions under which capture and culture

6 Barange et al. Impacts of climate change on marine ecosystem production in fisheries dependent societies 
152 fisheries would allow current per capita fish consumption rates in the near future ${ }^{4}$. Results

153 suggest that sustaining fish consumption rates is feasible even in a changing climate. This is,

154 however, contingent on a number of conditions, including the assumption of a sustainability

155 transition in fisheries management across all regions and ecosystem components, reductions in

156 the use of wild fish in the animal feed industry, and a fishmeal trade that stabilizes price and

157 distribution despite regional fluctuations in availability ${ }^{4}$.

158

159 These assumptions are optimistic but not utopian. There are demonstrated successes in

160 managing both industrial and artisanal fisheries in developed and developing countries ${ }^{2}$.

161 Farming of shellfish, herbivorous and omnivorous species is rising. Rapid technological

162 innovation, for example in the development of microalgal foods, is reducing aquaculture's

163 dependence on wild stocks ${ }^{25}$.

164

165 In summary, by developing and linking models of physical, biological and human responses to

166 climate change, we can predict impacts on fish yields and dependent societies. Our adoption of

167 highly-resolved shelf-sea physical-biological models rather than GCMs gives greater confidence

168 in predicting consequences at national scales, although there are significant trade-offs. As

169 demand for fish continues to grow, we suggest that linked social-ecological assessments such

170 as this are essential tools to guide the development of adaptation measures. Conclusions from

171 this analysis provide a relatively positive message about adaptation through 2050. Despite

172 projected increases in human population and per capita fish consumption rates, projected global

173 fish demands could be met, contingent on successful implementation of strategies for

174 sustainable harvesting, ongoing technological development in the aquaculture industry and

175 effective distribution of wild fish products from nations with a surplus to those with a deficit.

176

7 Barange et al. Impacts of climate change on marine ecosystem production in fisheries dependent societies 


\section{8• Methods}

\section{Physical- Biological models}

180 We simulated coastal and shelf-sea processes, primary, and secondary production, by means of a three-dimensional,

181 high-resolution $\left(0.1^{\circ} \times 0.1^{\circ}\right)$, hydrodynamic model $\left(\mathrm{POLCOMS}{ }^{26}\right)$, coupled with a generic, functional type ecosystem

182 model (ERSEM) ${ }^{27}$. The coupled model was run under three particular experiments: a) a present-day control experiment,

183 b) a near-future climate experiment (ca 2050) using data taken from IPCC SRES A1B emissions scenario (business-as-

184 usual, using the IPSL-SM4 OA-GCM), and c) re-analysis simulation using data from a global ocean assimilation and re-

185 analysis simulation ${ }^{17}$. Differences in ten-year means were considered as indicative of climate change, while recognizing

186 that climate variability may contribute to these differences. The outputs of these models were used to drive a size-

187 structured ecosystem mode ${ }^{28}$ that explicitly accounts for food web interactions, linking primary production to fish

188 production through predation, to project climate-driven changes in potential fish production. This modelling framework

189 was applied to 11 coastal and shelf sea regions, covering 30 Large Marine Ecosystems and including 67 marine

190 national Exclusive Economic Zones (EEZ). With this modelling structure, we obtained fine-scale temperature, primary

191 production and size-based estimates of biological production change by 2050, referenced to present day, for an area

192 currently yielding $77 \%$ of the global landings recorded from EEZs (see Supplementary material 1 ,

193 www.seaaroundus.org, ). The use of size-based models recognizes that in marine environments predation is strongly

194 driven by body size rather than taxonomic identity, and that direct climate change impacts are likely to be on ecological

195 and physiological relationships that are size and temperature dependent, but overlooks processes linked to species

196 identity. For each EEZ and scenario, the model was first run to equilibrium using time-averaged input before applying

197 the model to time-varying environmental conditions for the duration of a 10-year time slice, under each of the scenarios.

198 The results used in this paper are time-averaged across a 10 year time slice during which the size spectrum model has

199 been dynamical forced using daily time-varying inputs of temperature (near sea floor and mixed layer depth), detritus

200 and the intercept of the plankton. The intercept of the size spectrum is determined by the temporal changes in

201 phytoplankton and microzooplankton biomass density, with the consequences that higher primary production leads to

202 size spectra with higher intercepts. Phytoplankton and microzooplankton functional groups (outputs of the POLCOMS-

203 ERSEM model) are assumed to occupy size ranges. Assuming invariant biomass in body mass log bins and a -1

204 numerical density slope across a size range of $10^{-14}$ to $10^{-4} \mathrm{~g}$ size margin, we estimated the intercept. Recent work has

205 shown that size spectrum dynamics can be influenced by the variation in intercepts, slopes and the size range of

206 phytoplankton, and our results may therefore be sensitive to these simplifying assumptions.

\section{Fisheries Dependency}

209 Vulnerability to climate change depends on three key elements: Exposure to the physical effects of climate change,

210 economic and social Dependency on the changing variable(s) and Adaptive Capacity to the changes. To investigate the

211 potential societal impact of climate-induced changes in fish production potential, we developed an index of fisheries

212 dependency of 58 nations defined as "the importance of fish and fisheries to the national economy and food security"

213 A country's dependence score was determined from global fisheries statistics ${ }^{29}$ by using three indicators measuring the

214 contribution that fisheries makes to the national diet, to employment and to gross domestic product. The national-scale

8 Barange et al. Impacts of climate change on marine ecosystem production in fisheries dependent societies 
215 indicators were standardized on a scale of 0 to 1 and averaged to generate an overall dependency score. The

216 dependency analysis builds on data obtained from UN FAO statistics (dietary contributions) and the Sea Around Us

217 project (economic contributions, www.searoundus.org), while contributions in terms of employment were obtained from

$218 \mathrm{FAO}^{29}$ and published literature ${ }^{30}$.

219

220 Modelling assumptions

221 We conduct a single, but dynamically consistent, future climate projection based around the sensitivity of the system to

222 this imposed change, but without an assessment of its likelihood. The forcing scenario (A1B) was chosen as it sits near

223 the middle of the envelope of projected CO2 emissions. The IPSL CM4 model sits close to the centre of spread of

224 CMIP3 models in terms of global temperature, and for the 2050 forecast horizon model uncertainty would be expected

225 to dominate over scenario uncertainty. We recognize that a different combination of OA-GCM and regional model would

226 have resulted in some quantitative differences in the results, and where there are competing processes in the models

227 these may lead to qualitative differences. 


\section{- Figure legends}

Figure 1. Results of the modelling runs for the shelf seas of 20 LMEs, showing changes in temperature (in ${ }^{\circ} \mathrm{C}$ ) of the mixed layer (a) and Total primary production (in \%, b), in 2050, referenced to the Present Day Control (PDC) scenario. Each map reflects 10 years of model outputs (modified from Merino et al. 2012, Glob. Environ. Chang. 22, 795-806, with permission from Elsevier).

Figure 2. Percentage changes in temperature of the mixed layer (MLDT) and biomass of different size classes of phytoplankton (a), and potential total and per size class fish catch (b), by Exclusive Economic Zone. Changes for 2050 are referenced to the Present-Day Control (PDC) scenario. Change in catch potential assumes that community fishing mortality is 0.8 in all model runs.

Figure 3. Overall national Dependency on fish and fisheries in the regions considered

Figure 4. Kobe plot of potential catch change (in \%, a measure of exposure to climate change) and national dependency to fisheries (combining food, economic and employment provision) per national EEZ. Circles correspond to the regional centroid, scaled by the expected population in the regions by 2050 . 


\section{Acknowledgements}

This work was funded by the UK Natural Environment Research Council's Quantifying and Understanding the Earth System programme as part of the 'QUEST-Fish' project (http://www.quest-fish.org.uk/). This is a contribution to the ICES-PICES Strategic Initiative on Climate Change impacts on Marine Ecosystems (SICCME).

\section{References}

1 Delgado, C. L., Wada, N., Rosegrant, M. W., Meijer, S. \& Ahmed, M. Fish to 2020: Supply and demand in changing global markets. (International Food Policy Research Institute and Worldfish Center, 2003).

2 Worm, B. et al. Rebuilding global fisheries. Science 325, 578-585.

3 Allison, E. H. et al. Vulnerability of national economies to the impacts of climate change on fisheries. Fish Fish. 10, 173-196 (2009).

4 Merino, G. et al. Can marine fisheries and aquaculture meet fish demand from a growing human population in a changing climate? Global Environ. Chang. 22, 795-806 (2012).

5 Sumaila, R. U., Cheung, W. W. L., Lam, V. W. Y., Pauly, D. \& Herrick, S. Climate change impacts on the biophysics and economics of world fisheries. Nature Clim. Change 1, 449-456 (2011).

6 Steinacher, M. et al. Projected 21st century decrease in marine productivity: a multimodel analysis. Biogeosciences 7, 979-1005 (2010).

7 Cheung, W. W. L., Dunne, J. \& Sarmiento, J. L. P., D. Integrating ecophysiology and plankton dynamics into projected maximum fisheries catch potential under climate change in the Northeast Atlantic. ICES J. Mar. Sci. 68, 1008-1018 (2011).

8 Cheung, W. W. L. et al. Large-scale redistribution of maximum fisheries catch potential in the global ocean under climate change. Glob. Change Biol. 16, 24-35 (2009).

9 Hawkins, E. \& Sutton, R. The potential to narrow uncertainties in regional Climate predictions. B. Am. Meteorol. Soc. 90, 1095-1107 (2009).

10 Holt, J., Wakelin, S., Lowe, J. \& Tinker, J. The potential impacts of climate change on the hydrography of the northwest European Continental shelf. Progr. Oceanogr. 86 (2010).

11 Watson, R., Kitchingman, A., Gelchu, A. \& Pauly, D. Mapping global fisheries: sharpening our focus. Fish Fish. 5, 168-177 (2004).

12 Stock, C. A. et al. On the use of IPCC-class models to assess the impact of climate on Living Marine Resources. Progr. Oceanogr. 88, 1-27 (2011).

11 Barange et al. Impacts of climate change on marine ecosystem production in fisheries dependent societies 

subtropical biome and contraction of the temperate and equatorial upwelling biomes in the North Pacific under global warming. ICES J. Mar. Sci. 68, 986-995 (2011). Lehodey, P., Senina, I., Calmettes, B., Hampton, J. \& Nicol, S. Modelling the impact of climate change on Pacific skipjack tuna population and fisheries. Climatic Change 119, 95-109 (2013).

15 Richardson, A. J. \& Schoeman, D. S. Climate impact on plankton ecosystems in the Northeast Atlantic. Science 305, 1609-1612 (2004).

16 Bopp, L., Aumont, O., Cadule, P., Alvain, S. G. \& Gehlen, M. Response of diatoms distribution to global warming and potential implications: A global model study. Geophys. Res. Lett. 32 (2005).

17 Blanchard, J. et al. Potential consequences of climate change for primary production and fish production in large marine ecosystems. Philos. T. R. Soc. B 367, 2979-2989 (2012).

18 Chassot, E. et al. Global marine primary production constrains fisheries catches. Ecol. Lett. 13, 495-505 (2010).

19 Woodworth-Jefcoats, P. A., Polovina, J. J., Dunne, J. \& Blanchard, J. Ecosystem size structure response to 21st century climate projection: large fish abundance decreases in the central North Pacific and increases in the California Current. Glob. Change Biol. 19, 724-733 (2012).

20 Lam, V. W. Y., Cheung, W. W. L., Swartz, W. \& Sumaila, U. R. Climate change impacts on fisheries in West Africa: implications for economic, food and nutritional security. Afr. J. Mar. Sci. 34, 103-117 (2012).

21 Jones, M., Dye, S. R., Pinnegar, J. K., Warren, R. \& Cheung, W. W. L. Modelling commercial fish distributions: Prediction and assessment using different approaches. Ecol. Model. 225, 133-145 (2012).

22 Bell, J. D. et al. Mixed responses of tropical Pacific fisheries and aquaculture to climate change. Nature Clim. Change, doi:10.1038/nclimate1838 (2013).

23 Wheeler, T. \& von Braun, J. Climate change impacts on global food security. Science 341, 508-513 (2013).

24 Garcia, S. M. \& Rosenberg, A. A. Food security and marine capture fisheries: characteristics, trends, drivers and future perspectives. Philos. T. R. Soc. B 365, 28692880 (2010).

25 Tacon, A. G. J. \& Metian, M. Global overview on the use of fish meal and fish oil in industrially compounded aquafeeds: Trends and future prospects. Aquaculture 285, 146-158 (2008).

26 Holt, J. et al. Modelling the global coastal ocean. Philos. T. R. Soc. A 367, 939-951 (2009). 
27 Allen, I., Holt, J., Blackford, J. \& Proctor, R. Error quantification of a high-resolution coupled hydrodynamic-ecosystem coastal-ocean model: Part 2. Chlorophyll-a, nutrients and SPM. J. Marine Syst. 68, 381-404 (2007).

28 Blanchard, J., Law, R., Castle, M. D. \& Jennings, S. Coupled energy pathways and the resilience of size-structured food webs. Theor. Ecol. 4, 289-300 (2011).

29 FAO 2012. The State of the World's Fisheries and Aquaculture. FAO, Rome, Italy.

30 Teh, L. C. L. \& Sumaila, R. U. Contribution of marine fisheries to worldwide employment. Fish Fish. 14, 77-88 (2013). 